\title{
Discovering what is lost and found
}

\author{
The Examined Life: How We Lose and \\ Find Ourselves \\ Stephen Grosz \\ Random House Canada; 2013
}

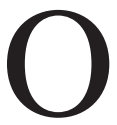

$\mathrm{f}$ the books I read during my residency, one that affected me greatly was Love's Executioner by Irvin Yalom. A collection of stories drawn from the author's experiences as a practising psychiatrist, it supported my hope that medicine was, or at least could be, the practice of hearing and understanding the narratives of patients. In the intervening years, I have read many similar books in which clinicians tell and retell stories of clinical encounters. Regardless the setting, patient narratives are situated at the core of clinical medicine. However, the calibre of descriptions vary, and essays often lack the key characteristic that makes the difference between reading a story and taking it in: some insight or truth that ties the specific to the universal and leads the reader to reflect on his or her life both as a practitioner and a person.

What a pleasure it was, then, to read The Examined Life: How We Lose and Find Ourselves. This collection of

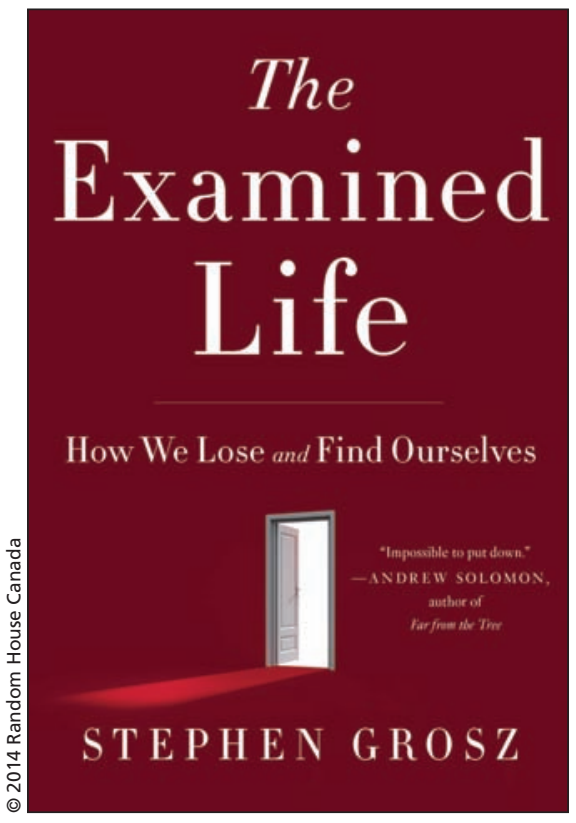

tionship at the centre of the book supports its inclusion in the genre of health humanities, but it could equally be argued that this is not a book of medical narratives because most of the patients are not really ill. A woman wonders if she should leave her boyfriend. A widow copes with grief. A man is boring to others. These are the little hardships of life that we in medicine may dismiss as trivial when

\section{A woman wonders if she should leave her boyfriend. A widow copes with grief. These are little hardships, but Grosz respects and honours them in a way that is more than just detached clinical observation.}

essays is the work of Stephen Grosz, a psychoanalyst living in London, England. In it, he describes the analytic care of a number of adults and children with what could be described as "problems of living." The presence of a helping rela- patients bring them up. In contrast, Grosz respects and honours the experiences and the people who relate them; in doing so, he connects the reader to the stories in a way that is more than just detached clin ical observation.
The essays are brief and simple, and the language is the spare prose of an analytic session. The narratives are grouped into categories such as "Beginnings," "Telling Lies" and "Changing"- action words that reflect the process-oriented nature of therapy. Given its subject matter, one might wonder if The Examined Life would be particularly of interest to therapists. However, the book is written for a general audience, and the fact that it has already appeared on the Sunday Times bestseller list in the United Kingdom speaks to its general appeal.

This is the sort of book that should probably be read slowly to allow opportunity for reflection. However, it is so engaging that it is easy to rush through it. The only thing that spoiled my enjoyment of this book was, oddly enough, that it is about psychoanalysis. It is not so much the theoretical underpinnings of psychoanalysis that I find off-putting, although dream analysis always seems a bit sketchy to me. Instead, it is the gruelling schedule of traditional analysis. I kept thinking: You saw that patient every day for how many years? Who was paying for this?

On the other hand, if I carefully and honestly examine my own motivations, I might have to admit that under all of my high-minded fiscal prudence and prudery, I envy Grosz his freedom. Working in the public health care system comes with certain restrictions. Wouldn't I enjoy a practice like he describes, with all the time in the world to examine the lives of others, uncovering what it is that they have lost and found?

\section{Lara Hazelton MD}

Psychiatrist

Halifax, NS

CMAJ 2014. DOI:10.1503/cmaj.131016 